\title{
The use of visible implant elastomer to permanently identify caecilians (Amphibia: Gymnophiona)
}

\author{
BENJAMIN TAPLEY ${ }^{1 *}$, CHRISTOPHER J. MICHAELS ${ }^{1}$, DAVID J. GOWER ${ }^{2} \&$ MARK WILKINSON ${ }^{2}$ \\ ${ }^{1}$ Zoological Society of London, Regents Park, London NW1 4RY, UK \\ ${ }^{2}$ The Natural History Museum, Cromwell Road, London, SW7 5BD, UK \\ ${ }^{*}$ Corresponding author e-mail: ben.tapley@zsl.org
}

\begin{abstract}
Identifying individual animals is important for studying populations and for the optimal management of individual animals in captivity. In the absence of natural markings that discriminate individuals, such identification may require animals to be marked by researchers. Amphibians are challenging subjects to mark due to their small size and sensitive, permeable and frequently shed skin. Visible Implant Elastomer (VIE) has been widely used to mark amphibians, but no long-term study has validated this technique in caecilian amphibians. We anaesthetised and attempted to VIE mark seven Herpele squalostoma and one Microcaecilia unicolor held at ZSL London Zoo. No specimens suffered ill effects of anaesthesia or VIE injection, but mean persistence of marks was 191 days in $H$. squalostoma suggesting that this marking technique is not suitable for identifying individuals of this species in the long-term. We were unable to inject VIE into the M. unicolor and/or the elastomer was not visible through the darkly pigmented skin. Further research is required to develop methods for long-term marking of a diversity of caecilians.
\end{abstract}

\section{INTRODUCTION}

dentifying individual animals facilitates the estimation of population size, and understanding population dynamics, home range, longevity and numerous other life history, ecological and biological characteristics (Donnelly et al., 1994). The identification of individuals is also important in the management of captive animals in laboratory, zoo and private settings. Furthermore, it may help understand and police the illegal wildlife trade (Buhlmann \& Tuberville, 1998). Individuals of some amphibian species have distinctive naturally occurring markings that may aid in discriminating individuals and in their reidentification over time. Identifications based on photographic records of natural markings are minimally invasive and have been used to identify individual amphibians in all three extant amphibian orders (Hagström, 1973; Bailey, 2004; Kramer et al., 2001; Bradfield, 2004, Kenyon et al., 2009). However, many amphibians do not have distinctive or temporally stable individual markings (Wengert \& Gabriel, 2006; Kraus \& Allison, 2009), and in such cases more invasive marking techniques may need to be adopted (see review by Ferner, 2007). Amphibians are particularly challenging candidates to mark due to their relatively small size, the permeability and sensitivity of their frequently shed skin and their often complex life cycles (Heemeyer et al., 2007).

Caecilians (Gymnophiona) are elongate limbless amphibians (see Wilkinson, 2012 for an introduction). They can be difficult to study because most species burrow in soil (Gower \& Wilkinson, 2005) and their limblessness and fossoriality means that they present fewer options for marking, and marks that have proven useful in other (anuran and caudatan) amphibians may be shed or may impair marked animals. Some caecilian species have markings that have been suitable for the generation of individual photographic identifications (Kramer et al., 2001) and the natural variation in annulation patterns in Dermophis mexicanus (Duméril \& Bibron, 1841) have been used to distinguish between members of a small population of captive animals (Wright \& Minott, 1999).

Previous work has shown that some marking techniques may be appropriate for identifying individual caecilians. These include the use of Panjet (Wright Health Group Ltd., Dundee; Measey et al., 2001; Measey \& Di Bernardo, 2003; Measey et al., 2003); freeze branding (Measey et al., 2001); soft visible implant alphanumeric tags (Measey et al., 2001, Measey et al., 2003; Gower et al., 2006) and visible implant elastomer (VIE; Measey et al., 2001). However, the long-term stability and visibility of any of these identifiers has not been determined for periods greater than 15 weeks (Measey et al., 2001; Measey \& Di Bernardo, 2003; Measey et al., 2003) and the longer-term, viability of the markings is unknown.

Most field applications of individual identification require a longer persistence of marks and so further investigation to identify viable marking techniques for caecilians is required. Moreover, the morphology, ecology and life history of caecilians varies widely among species (e.g. Taylor, 1968; Wilkinson \& Nussbaum, 2006; Gower \& Wilkinson, 2005; San Mauro et al., 2014), and so an expansion of marking trials to more taxa is also necessary in order to better design appropriate marking techniques for Gymnophiona.

VIE is a liquid polymer that solidifies when mixed with a curing agent. The polymer is coloured and fluoresces under black light (UVA light) and can be injected superficially 
into animals to create individual marks for identification. VIE is commonly used to mark amphibians and has gained popularity in recent years. Bailey (2004) reported a $100 \%$ VIE mark retention rate in 36 marked salamanders (Eurycea bislineata) over 44 weeks. A $100 \%$ VIE retention rate was also reported for laboratory housed E. bislineata over 15 weeks (Marold, 2001). Other studies have questioned the reliability of VIE for marking amphibians; Brannelly et al. (2013) reported that VIE tag movement occurred within one week in $50 \%$ of the tags implanted into the toad Nectophrynoides asperginis, and VIE tag movement and loss was reported in a study by Brannelly et al. (2014) evaluating marking techniques for the tree frog Litoria verreauxii alpina.

Very few population parameter estimates for caecilians have been made and there have been limited attempts to test field methods representing barriers to further research and caecilian conservation (Gower \& Wilkinson, 2005). Maintaining caecilians in captivity provides an opportunity to study caecilians and develop and validate methods that can be used to understand and conserve them (Wake, 1994; O’Reilly, 1996; Wilkinson et al., 2013; Maddock et al., 2014, Tapley et al., 2014, 2018; Rendle et al., 2014). To test the application of VIE as a method to permanently identify individual caecilians, we attempted to mark captive Herpele squalostoma (Stutchbury, 1836) and Microcaecilia unicolor (Duméril, 1863) with VIE and to determine how long marks remain visible.

\section{MATERIALS AND METHODS}

\section{Ethics}

This study was compliant with the BHS Ethics Policy (British Herpetological Society, 2017). Ethical approval to mark caecilians with VIE using the described methods was granted by the ZSL ethics committee (Project ZDZ17). The methods used to mark caecilians here, including anaesthesia and recovery did not, in this context, require a Home Office License as a) VIE is a routine marking technique for amphibians, and even though it has been little used in caecilians it is the most routine marking type for use in this group, and b) animals were marked opportunistically as part of a routine veterinary health examination for which they needed to be restrained and anaesthetised.

\section{Study species}

The Congo caecilian ( $H$. squalostoma; Family Herpelidae) is a burrowing caecilian from lowland forests in southeastern Nigeria, Cameroon, south-western Central African Republic, mainland Equatorial Guinea, Gabon, Congo, western Democratic Republic of Congo, and Bioko Island in Equatorial Guinea (IUCN SSC Amphibian Specialist Group, 2018). The species is oviparous (Kouete et al., 2013) and exhibits maternal dermatophagy; young receive extended parental care and have specialised deciduous teeth that they use to remove and eat the stratum corneum of maternal skin (Kouete et al., 2012). The black micro caecilian (M. unicolor; Family Siphonopidae) is a poorly known species (BittencourtSilva \& Wilkinson, 2018) that is likely a dedicated burrower (Wilkinson et al., 2013, Bardua et al., 2019) and is known with certainty only from French Guiana (Wilkinson \& Kok, 2010). Reproductive mode is oviparity (San Mauro et al. 2014) and, based on other siphonopids, can be inferred to involve direct development (i.e. no larval stage) and maternal dermatophagy (Wilkinson et al., 2008, 2013).

\section{Husbandry}

In 2008, ZSL London Zoo acquired $H$. squalostoma via donation, the animals were long-term wild collected captives that had been imported directly to the UK by a licensed importer. A further four juveniles were loaned to ZSL London Zoo in October 2014. These individuals were legally collected as eggs by Marcel Koute from Nkong in the central region of Cameroon in June 2013 and hatchlings raised by MW. Microcaecilia unciolor specimens were legally collected from the Core Mountains at Camp Patawa between 2008 and 2010 by the authors (DG \& MW) and transferred to ZSL London Zoo in 2013. Both $H$. squalostoma and M. unicolor were maintained at ZSL London Zoo as part of a collaborative project with the Natural History Museum's Herpetology Research Group aimed at refining methods for caecilian husbandry, developing and validating field methods, and discovering aspects of life history and behaviour.

Microcaecilia unicolor and $H$. squalostoma of unknown sex were housed in a dedicated, climate-controlled facility. Room temperature ranged from $24-27{ }^{\circ} \mathrm{C}$. Herpele squalostoma were maintained in two groups in separate enclosures and $M$. unicolor were housed individually. All enclosures were glass and custom-made (56 ×56 × $35 \mathrm{~cm}$ ) with slanted bottoms to create a humidity gradient. Part of the lid consisted of a fine mesh for ventilation. Specimens were provided with a $15 \mathrm{~cm}$ deep layer of Megazorb (Northern Crop Driers (UK) Ltd.) substrate (Tapley et al., 2014) a waste product from the paper making industry which contains unbleached, wood derived cellulosic fibre and inorganic pigment (Kaolin and calcium carbonate), which is sold for equine husbandry. Dry Megazorb was soaked in water for 24 hrs until saturated. Specimens were fed three times per week with live worms (Lumbricus sp. and Eisenia sp.). Herpele squalostoma were occasionally also offered freshly killed crickets (Gryllus bimaculatus and $G$. assimilis) left on the surface of the substrate.

\section{Marking}

To observe and monitor any potential detrimental effects of marking, $H$. squalostoma were marked in two batches, seven months apart. We also attempted to mark a single $M$. unicolor. Caecilians were anaesthetised by a ZSL veterinarian for a routine veterinary health examination. Caecilians were anaesthetised in either buffered tricaine methanesulfonate 1g/L (PHARMAQ Ltd., Hampshire, UK) or $4 \%$ isoflurane (Zoetis Inc., New Jersey, USA) in oxygen in a plastic bag (details to presented elsewhere) in order to prevent injury during the marking process because unanaesthetised caecilians are extremely difficult to manually restrain. VIE elastomer and a curing agent (Northwest Marine Technology Inc., Shaw Island, Washington, USA), were prepared following the manufacturer's guidelines and mixed in a 10:1 ratio. Using an insulin syringe and needle (BD U-100 Insulin $0.3 \mathrm{~mL} /$ 
$\mathrm{cc})$, approximately $0.05 \mathrm{ml}$ of the prepared elastomer was injected subcutaneously into the dorsal surface one third of the distance between head and terminus. Each caecilian was marked with a different coloured VIE. Elastomers were implanted between annular grooves. The needle was inserted perpendicular to the long axis of the body with the needle tip pointing towards the vertebrae, then rotated to a nearparallel orientation to the skin surface and advanced at a low angle of insertion underneath the skin for c. 8-10 mm. Even pressure was then applied to the plunger of the syringe to extrude VIE while the needle was slowly withdrawn, creating a linear mark. Pressure was removed from the plunger c. 2-3 $\mathrm{mm}$ from the injection site so that the trail of VIE stopped well before the injection aperture; failing to do so can result in the solidified mark being extruded through the aperture.

During the procedure, animals were laid out on an absorptive disposable bed pad soaked with amphibian Ringer's solution (Wright \& Whitaker, 2001), and frequently rinsed with the same solution in order to avoid dehydration and damage to the skin. Animals recovered from anaesthesia in a container of shallow amphibian Ringer's solution and were not returned to their enclosures until they had a normal righting reflex and exhibited a normal response to aversive stimuli (a gentle pinch). Post-recovery, the marked caecilians were weighed (to the nearest $0.1 \mathrm{~g}$ ), using Pesola spring scales before being released back into their original enclosures where they were housed in two groups. Animals were subsequently periodically checked for the presence of the VIE marks and were weighed each time they were checked. They were checked infrequently in order to minimise disturbance to the animals and to the substrate, including any possible burrow structures. The last date that a marking was recorded as being visible was used as the minimum estimate of mark retention.

\section{RESULTS}

All H. squalostoma were successfully marked (Figs. 1A \& $B)$, although the marking in one animal was not visible the day after marking. We were unable to mark the single $M$. unicolor because we were unable to get the needle to form a channel into which VIE could be freely injected. Attempts to mark further $M$. unicolor were not made as the method was deemed non-viable in this species based on the initial trial.

In H. squalostoma, VIE mark retention ranged from 0-422 days (Table 1). On average, marks remained visible for 191 days with a standard deviation of 169.9 days. Mean average
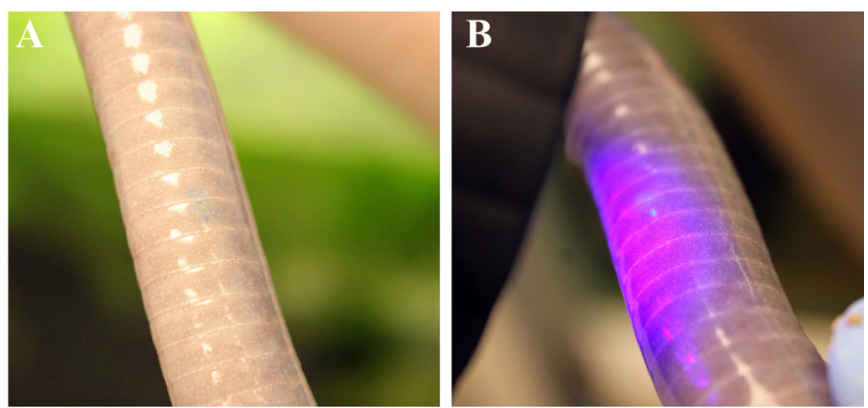

Figure 1. A) VIE marking in H. squalostoma in ambient light, B) VIE marking in $\mathrm{H}$. squalostoma under black light
Table 1. VIE mark retention and weight change in $H$. squalostoma

\begin{tabular}{|cccc|}
\hline Specimen ID & $\begin{array}{c}\text { Colour of } \\
\text { marking }\end{array}$ & $\begin{array}{c}\text { Minimum } \\
\text { duration mark } \\
\text { visible (days) }\end{array}$ & $\begin{array}{c}\text { Weight change } \\
\text { over marking } \\
\text { period (g) }\end{array}$ \\
\hline ZRS16-08880 & Orange & 422 & +35.9 \\
ZRS16-08881 & Pink & 197 & -5.1 \\
ZRS16-08882 & Green & 42 & +0.6 \\
ZRS16-08883 & Cherry red & 422 & +30.6 \\
ZRS15-08651 & Red & 128 & +26.6 \\
ZRS15-08652 & Green & 0 & -2.0 \\
ZRS15-08653 & Blue & 128 & +20.8 \\
\hline
\end{tabular}

body weight change between being marked and the date that the mark was last observed was $+15.3 \mathrm{~g}$, and although both weight gains and losses were measured, losses were fewer and generally smaller. No animal showed any clinical signs associated with marking. The single $M$. unicolor also recovered well from the failed marking attempt (where the needle punctured the skin but no VIE was deposited) with no clinical signs of ill health observed.

\section{DISCUSSION}

Our data suggest that VIE tags might not be appropriate for marking $H$. squalostoma when individuals need to be identified in long-term studies. The colour of the mark could have been a factor but as only one animal was marked with each colour it is not possible to associate VIE colour and mark retention. In $\mathrm{H}$. squalostoma, mark retention was highly variable between individuals. Furthermore, marks were not always easily visible, even when illuminated under a black light and many marks were found only after repeatedly inspecting the animal. This marking technique would be impractical for field use because anaesthesia is required for implantation, and ideally animals should be monitored for 24 hours after implantation to assess anaesthetic recovery status and mark retention (given that one mark was immediately lost in one of our marked individuals). Moreover, due to the difficulty in finding marks known to be present, differentiation between marked and unmarked animals may be problematic in the field even where marks persist. However, this could be ameliorated if all caecilians were marked in exactly the same location of the body.

The VIE marks in $H$. squalostoma did not migrate as reported in some marking trials of other amphibians (e.g. Brannelly et al., 2013, 2014). It is unclear how caecilians lost the marks in this study; no marks were found on a postmortem examination of an animal that died of natural causes over a year after the mark was last observed. This might indicate ejection, absorption, or micro-fragmentation of the VIE tag.

We were unsuccessful in our single attempt to mark a M. unicolor. Both $H$. squalostoma and $M$. unicolor have dermal scales in annular folds, (Nieden, 1912; Taylor, 1968; Zylberberg \& Wake, 1990), but squamation is much less extensive anteriorly in $H$. squalostoma, and this might be 
causally related to the difficulty of inserting the elastomer in M. unicolor. Ichthyophiidae and Rhinatrematidae also exhibit extensive squamation (Colbert, 1955; Zylberberg et al., 1980), consequently VIE marking would likely be difficult in these taxa. The skin of $M$. unicolor is much more darkly pigmented than the skin of $H$. squalostoma, this could have obscured the visibility of any traces of VIE that might have been injected. We also found it difficult to track the applicator needle at a very shallow depth under the skin in this species.

While our sample size was small and limited to two species representing two of the ten caecilian families; this is the first attempt to validate longterm VIE marking in caecilian amphibians. This method is viable for shorter term studies of at least $H$. squalostoma, given that most animals retained marks and none showed any ill effects of having been anaesthetised and marked. However, its utility for the long-term study of any caecilian species is at best uncertain but warrants further research.

Dark skin pigmentation and possibly other morphological features, such as squamation, may preclude the efficient use of subcutaneous marking techniques in some caecilians. Thus alternative techniques should be developed to permanently identify individual $H$. squalostoma and $M$. unicolor for longterm studies. Natural variation in annulation patterns might be useful in this respect as they have in D. mexicanus (Wright \& Minott, 1999).

\section{ACKNOWLEDGEMENTS}

Permits for export of samples were provided by Direction de l'Environment de l'Aménagement et du Logement and the Direction des Services Vétérinaires de la Guyane, Cayenne, French Guiana. We are grateful to Myriam Virevaire and Le Comité Scientifique Régional du Patrimonie Naturel for supporting our research in French Guiana. For companionship and/or practical assistance in organising and executing laboratory and fieldwork we thank Elodie Courtoise, Antoine Fouquet, Philippe Gaucher, Fausto Starace and family, and Jeannot and Odette (Camp Patawa). We are grateful to the ZSL London Zoo Wildlife Health Team with the marking procedure and Amanda Guthrie for her comments on the draft of this manuscript. We would also like to thank all members of the Herpetology team at ZSL London Zoo who assisted in the husbandry of the animals in this work.

\section{REFERENCES}

Bailey, L.L. (2004). Evaluating elastomer marking and photo identification methods for terrestrial salamanders: marking effects and observer bias. Herpetological Review 35: 38-41.

Bittencourt-Silva, G. B. \& Wilkinson, M. (2018). First record of predation on the caecilian Microcaecilia unicolor (Duméril, 1863). Herpetology Notes 11: 641-644.

Bradfield, K. (2004) Photographic identification of individual Archey's frogs, Leiopelma archeyi, from natural markings. DOC Science Internal Series 191. New Zealand Department of Conservation, Wellington, $36 \mathrm{pp}$.
Brannelly, L.A., Chatfield, M.W. \& Richards-Zawacki, C. (2013). Visual implant elastomer (VIE) tags are an unreliable method of identification in adult anurans. Herpetological Journal 23: 125-129.

Brannelly, L.A., Berger, L. \& Skerratt, L.F. (2014). Comparison of three widely used marking techniques for adult anuran species Litoria verreauxii alpina. Herpetological Conservation and Biology 9:428-435.

British Herpetological Society (2017). British Herpetological Society: Ethical policy and guidelines. The Herpetological Bulletin 141: 46-48.

Buhlmann, K. \& Tuberville, T.D. (1998). Use of passive integrated transponder (PIT) tags for marking small freshwater turtles. Chelonian Conservation and Biology 3: 102-104.

Colbert, E.H. (1955). Scales in the Permian amphibian Trimerorhachis. American Museum Novitates 1740: 1-17.

Donnelly, M.A., Guyer, C., Juterbock, E.J. \& Alford, R.A. (1994). Techniques for marking amphibians. In: Measuring and monitoring biological diversity: standard methods for amphibians, pp. 277-284. Heyer, W. R. (Ed.). Washington DC: Smithsonian Institution Press.

Duméril, A.H.A. (1863). Catalogue méthodique de la collection des batracians dy Muséum D'Historie Naturalle de Paris. Mémoires de la Société Impériale des Sciences Naturalles de Cherbourg 9: 295-321.

Duméril, A.M.C. \& Bibron, G. (1841). Erpétologie Genérale ou Histoire Naturelle Complète des Reptiles. Volume 8. Paris: Librarie Enclyclopedique de Roret, 430 pp.

Ferner, J.W. (2007). A review of marking and individual recognition techniques for amphibians and reptiles. Salt Lake City: Society for the Study of Amphibians and Reptiles, $72 \mathrm{pp}$.

Fry, D.B. (1915). Herpetological notes. Proceedings of the Royal Society of Queensland 27: 60-95.

Gower, D.J. \& Wilkinson, M. (2005). The conservation biology of caecilians. Conservation Biology 19: 45-55.

Gower, D.J., Oommen, O.V. \& Wilkinson, M. (2006). Marking amphibians with alpha numeric fluorescent tagscaecilians lead the way. Herpetological Review 37: 302303.

Green, J. (1818). Descriptions of several species of North American Amphibia, accompanied with observations. Journal of the Academy of Natural Sciences of Philadelphia 1: 348-359.

Hagström, T. (1973). Identification of newt specimens (Urodela, Triturus) by recording the belly pattern and a description of photographic equipment for such registrations. British Journal of Herpetology 4: 321-326.

Heemeyer, J.L., Homyack, J.A. \& Haas, C.A. (2007). Retention and readability of visible implant elastomer marks in eastern red-backed salamanders (Plethodon cinereus). Herpetological Review 38: 425-428.

IUCN SSC Amphibian Specialist Group (2018). Herpele squalostoma. The IUCN Red List of Threatened Species 2018: e.T59565A16958011. http://dx.doi.org/10.2305/ IUCN.UK. 2018-1.RLTS.T59565A16958011.en . Downloaded on 24 July 2019.

Kenyon, N., Philott, A.D. \& Alford, R. (2009). Evaluation of the 
photographic identification method (PIM) as a tool to identify adult Litoria genimaculata (Anura: Hylidae). Herpetological Conservation and Biology 4: 403-410.

Kouete, M. T., Wilkinson, M. \& Gower, D. J. (2012). First reproductive observations for Herpele Peters, 1880 (Amphibia: Gymnophiona: Herpelidae): evidence of extended parental care and maternal dermatophagy in $H$. squalostoma (Stutchbury, 1836). ISRN Zoology 269690. doi:10.5402/2012/269690

Kouete, M.T., Ndeme, E.S. \& Gower, D.J. (2013). Further observations of reproduction and confirmation of oviparity in Herpele squalostoma (Stutchbury, 1836) (Amphibia: Gymnophiona: Herpelidae). Herpetology Notes 6: 583-586.

Kramer, A., Kupfer, A. \& Himstedt, W. (2001). Haltung und Zucht der thailändischen Blindwühle Ichthyophis kohtaoensis (Amphibia: Gymnophiona: Ichthyophiiidae). Salamandra 37: 1-10.

Kraus, F. \& Allison, A. (2009). A remarkable ontogentic change in color pattern in a new species of Oreophryne (Anura: Microhylidae) from Papua New Guinea. Copeia 2009: 690-697.

Maddock, S.T., Lewis, C.J., Wilkinson, M., Day, J.J., Morel, C. \& Kouete, M.T., \& Gower, D.J. (2014). Non-lethal DNA sampling for caecilian amphibians. The Herpetological Journal 24: 255-260.

Measey, G.J., Gower, D.J., Oommen, O.V. \& Wilkinson, M. (2001). Permanent marking of a fossorial caecilian, Gegeneophis ramaswamii (Amphibia: Gymnophiona: Caeciliidae). Journal of South Asian Natural History 5: 141-147.

Measey, G.J. \& Di-Bernardo, M. (2003). Estimating juvenile abundance in a population of the semiaquatic caecilian, Chthonerpeton indistinctum (Amphibia: Gymnophiona: Typhlonectidae), in southern Brazil. Journal of Herpetology 37: 371-374.

Measey, G.J., Gower, D.J., Oommen, O.V. \& Wilkinson, M. (2003). A mark-recapture study of the caecilian amphibian Gegeneophis ramaswamii (Amphibia: Gymnophiona: Caeciliidae) in southern India. Journal of Zoology 261: 129-133.

Marold, M.A.R. (2001). Evaluating visual implant elastomer polymer for marking small, stream-dwelling salamanders. Herpetological Review 32: 91-92.

Nieden, F. (1912). Übersicht über die afrikanischen Schleichenlurche (Amphibia: Apoda). Sitzungsberichte der Gesellschaft Naturforschender Freunde zu Berlin 1912: 186-214.

O’Reilly, J.C. (1996). Keeping caecilians in captivity. Advances in Herpetoculture 1: 39-45.

Poynton, J.C., Howell, K.M., Clarke, B.T. \& Lovett, J.C. (1999). "1998" A critically endangered new species of Nectophrynoides (Anura, Bufonidae) from the Kihansi Gorge, Udzungwa Mountains, Tanzania. African Journal of Herpetology 47: 59-67.

Rendle, M.E., Tapley, B., Perkins, M., Bittencourt-Silva, G., Gower, D.J. \& Wilkinson, M. (2015). Itraconazole treatment of Batrachochytrium dendrobatidis (Bd) infection in captive caecilians (Amphibia: Gymnophiona) and the first case of $B d$ in a wild neotropical caecilian. Journal of Zoo and Aquarium Research 3: 137-140.

San Mauro, D., Gower, D.J., Müller, H., Loader, S.P., Zardoya, R., Nussbaum, R.A., Wilkinson, M. (2014). Life-history evolution and mitogenomic phylogeny of caecilian amphibians. Molecular Phylogenetics and Evolution 73: 177-189.

Stutchbury, S. (1836). "1834". Description of a new species of the genus chameleon. Transactions of the Linnean Society. London 17: 361-362.

Tapley, B., Bryant, Z., Grant, S., Kother, G., Feltrer, Y., Masters, N., Strike, T., Gill, I., Wilkinson, M. \& Gower, D.J. (2014). Towards evidence based husbandry for caecilian amphibians: substrate preference in Geotrypetes seraphini (Amphibia: Gymnophiona: Dermophiidae). Herpetological Bulletin 129: 15-18.

Tapley, B., Michaels, C.J., Gower, D.J. \& Wilkinson, M. (2018). Filling in the blanks, the role of caecilians in Zoo collections. BIAZA News Summer Edition : 26.

Wake, M.H. (1994). Caecilians (Amphibia: Gymnophiona) in captivity. In: Captivity and Management and Conservation of Reptiles and Amphibians, pp. 223-228. Murphy, J.B., Alder, K. \& Collins, J.T. (Eds.). London, UK: Society for the study of Reptiles and Amphibians.

Wengert, G.M. \& Gabriel, M.W. (2006). Using chin spots patterns to identify individual mountain yellow-legged frogs. Northwestern Naturalist 87: 192.

Wilkinson, M. (2012). Quick guide: Caecilians. Current Biology 22: R668-669.

Wilkinson, M. \& Kok, P.J.R. (2010). A new species of Microcaecilia (Amphibia: Gymnophiona: Caeciliidae) from Guyana. Zootaxa 2719: 35-40

Wilkinson, M. \& Nussbaum, R. A. (2006). Caecilian phylogeny and classification. In: Reproductive Biology and Phylogeny of Amphibia, Volume 3. Gymnophiona, pp. 39-78. J.-M. Exbrayat (Ed.) Science Publishers Inc.

Wilkinson, M., Kupfer, A., Marques-Porto, R., Jeffkins, H., Antoniazzi, M. M. \& Jared, C. (2008). One hundred million years of skin feeding? Extended parental care in a Neotropical caecilian (Amphibia: Gymnophiona). Biology Letters 4: 358-361.

Wilkinson, M., Sherratt, E., Starace, F. \& Gower, D.J. (2013). A new species of skin-feeding caecilian and the first report of reproductive mode in Microcaecilia (Amphibia: Gymnophiona: Siphonopidae). PLoS ONE 8: e57756.

Wright, K.M. \& Minott, T. (1999). Individual identification of captive Mexican caecilians (Dermophis mexicanus). Herpetological Review 30: 32-33.

Wright, K.M. \& Whitaker, B.R. (2001). Amphibian Medicine and Captive Husbandry. Malabar: Krieger. 570 pp.

Zylberberg, L., Castanet, J. \& De Ricqles, A. (1980). Structure of the dermal scales in Gymnophiona (Amphibia). Journal of Morphology 165: 41-54.

Zylberberg, L. \& Wake, M.H. (1990). Structure of the scales of Dermophis and Microcaecilia (Amphibia: Gymnophiona) and a comparison to dermal ossifications of other vertebrates. Journal of Morphology 206: 25-43.

Accepted: 8 November 2019 